\title{
Regimes de valor, regimes de conhecimento: Alguns temas da antieconomia da dádiva
}

\author{
Gilson R. de M. Pereira*
}

\begin{abstract}
RESUMO: O estudo das homologias estruturais dos campos, das especificidades dos interesses e das estratégias empregadas pelos agentes, bem como os estudos da lógica do quasi-market e da troca de dádivas como tipo modelar de intercâmbios não explicitamente econômicos, lança luz nas relações entre o campo simbólico e o econômico, entre os valores e os saberes, podendo resultar num conjunto de conhecimentos capazes de redimensionar os problemas do campo educacional advindos dos desafios postos à cidadania, simultaneamente nas esferas intra e extramercado.
\end{abstract}

Palavras-chave: Valor, conhecimento, dádiva, educação, mercado

\section{Introdução}

A hipótese de que na vida social há diferentes regimes de valor, ou seja, de que o valor não se reduz à sua dimensão econômica, à criação de valor, ao processo de valorização, circulação e acumulação de riquezas etc., de que os interesses e as estratégias dos agentes sociais não se reduzem aos prevalecentes no campo econômico - cuja máxima que orienta os lucros e minimiza as perdas é a célebre divisa business is business -, de que, por conseguinte, uma parte considerável de nossas vidas é regida por regularidades cuja lógica não se escora na troca de equivalentes, de que, ainda, não temos somente uma moral de mercadores (Mauss 1995, p. 258), e de que aos diversos regimes de valor correspondem diversos regimes de conhecimento, ou seja, diferentes formas de conhecer e praticar o conheci-

\footnotetext{
* Docente da faculdade de Educação na Universidade Regional do Rio Grande do Norte. E-mail:
} gilsonmp@uol.com.br 
mento, não é, de modo algum, surpreendente. Basta consultar o dicionário para se dar conta da multiplicidade de ocasiões práticas nas quais o valor é referido. $O$ surpreendente talvez seja a afirmação segundo a qual a lógica do campo econômico ilumina a lógica da produção de bens tão pouco econômicos, no sentido estrito do termo, quanto a produção simbólica em geral. Também é surpreendente sustentar que a produção simbólica lance luz nas práticas mais corriqueiras do universo propriamente econômico. Mas essas surpresas são superadas à medida que consideramos a idéia, defendida por Bourdieu, de que há homologias estruturais entre os campos, de que campos tão diferentes entre si como o político, o da alta-costura, o filosófico etc. têm leis invariantes passíveis de apreensão por meio de uma teoria geral dos campos. As propriedades gerais dos campos iluminam as propriedades de cada campo em particular e as propriedades particulares de cada campo iluminam as propriedades particulares de outros campos. Como os campos, embora mais ou menos autônomos, não são universos isolados, a teoria geral dos campos constitui um forte recurso na análise do estado dos campos simbólicos, como é o caso do educacional, em sociedades nas quais a esfera econômica tende a impor em tudo juízos de validação e valores.

Nas notas a seguir, são analisados traços iniciais de uma pesquisa atualmente em andamento pelo programa de pós-graduação da Faculdade de Educação da USP, tomando como modelo a troca de dádivas, forma de troca na qual o preço (expressão monetária do valor da mercadoria, no sentido econômico estrito) está ausente ou desempenha um papel muito indireto. Argumenta-se que o estudo dessa modalidade de troca, amplamente praticada em nossas sociedades, como o foi em sociedades arcaicas, permite compreender as práticas que se dão em universos aparentemente bastante separados, tais como o familiar, o escolar, o artístico, o científico etc. Posteriormente discutem-se, embora sem disso tirar conclusões sistemáticas, as ligações práticas das formas de valor com os interesses e as estratégias dos agentes, bem como com o âmbito do conhecimento, ou melhor, da produção simbólica em geral e da educação, em particular.

\section{O valor das coisas: Dimensão simbólica}

A troca de dádivas foi descrita pela primeira vez por Mauss em seu célebre Essai sur le don, publicado em 1923. Trata-se, essencialmente, do seguinte: analisando comparativamente uma razoável quantidade de material etnográfico, Mauss descobriu que os habitantes das sociedades ar- 
caicas da orla do Pacífico e do noroeste da América do Norte, que compunham um cenário cultural extremamente diversificado, praticavam um tipo de intercâmbio de prestações e de contraprestações, denominadas pelo autor de "prestações totais", caracterizadas basicamente pela oferenda de presentes, voluntária, livre e gratuita, e, simultaneamente, interessada e obrigatória. Buscando trazer à luz as regras jurídicas e morais vigentes nessas transações, responsáveis pelo fato de o presente recebido ser (livre e) obrigatoriamente retribuído, Mauss chegou a um conjunto de resultados (alguns mais, outros menos desenvolvidos no Essai) ${ }^{1}$ :

- $1^{\circ}$ Tema: Não há nunca um mercado entre indivíduos. As dádivas são, antes de mais nada, caracterizadas pela presença de personagens coletivos que compactuam no intercâmbio: são clãs, tribos, famílias que se opõem no mercado de dádivas por intermédio de seus chefes ou em grupos ou desses dois modos simultaneamente;

- $2^{\circ}$ Tema: Não são apenas riquezas que são trocadas, ou seja, bens econômicos no sentido estrito, mas sobretudo "delicadezas, festins, ritos, serviços militares, mulheres, crianças, danças, festas, feiras cujo mercado é apenas um dos momentos e no qual a circulação de riquezas é apenas um dos termos de um contrato muito mais geral e muito mais permanente" (Mauss 1995, p. 151);

- $3^{\circ}$ e $4^{\circ}$ Temas: (liberdade e) obrigação de dar e (liberdade e) obrigação de receber. Nas regras de direito e moral dessas culturas, não presentear e não aceitar o presente dado implicam um rompimento com as normas de sociabilidade comuns: é o maior de todos os acintes, cujo revide pode ser tremendo, como a guerra. No entanto, embora seja obrigatório, a pessoa é livre para entrar ou não no circuito das dádivas (livre para entrar no jogo, iludir-se). Cabe então perguntar: o que faz a pessoa presentear (iniciar, portanto, a seqüência de dons e contradons) sem esperar retribuição (a liberdade do outro de não retribuir é sempre resguardada) e o que a faz, invariavelmente, retribuir o presente recebido?

- $5^{\circ}$ Tema: Todo presente recebido deve ser (livre e) obrigatoriamente retribuído;

- $6^{\circ}$ Tema: Entre a dádiva e a contradádiva interpõe-se um intervalo temporal. 
Inicialmente, pode-se fazer aqui uma observação a respeito do aspecto aparentemente arbitrário da troca de dádivas. Dar livremente sem nada esperar em troca, mas de certo modo coagido a fazê-lo, retribuir livremente, também submetido a coações difusas, expulsar da reciprocidade de dádivas, sem bem o saber, ou seja, sem cálculo consciente, os interesses mais larvares da economia, ter interesses nunca confessados, ou seja, incorporados como mentira para si e para os outros - "ficção, formalismo e mentira social" (Mauss 1995 , p. 147) -, em práticas aparentemente tão desinteressadas, tudo isso constitui "um problema sociológico delicado e pouco claro, ligado essencialmente ao caráter equívoco, e até contraditório, desta relação" (Pouillon 1995, p. 95). O caráter fugidio, complexo e de difícil apreensão da troca de dádivas fica mais patente quando consideramos o intervalo temporal entre a prestação e a contraprestação. Retribuir imediatamente equivale a recusar o presente recebido; os agentes, então, interpõem, sem cálculo consciente, um intervalo de tempo entre o dar e o retribuir, fazendo com que a prestação e a contraprestação pareçam duas séries independentes, ambas irredutíveis em sua generosidade. ${ }^{2}$ Além disso, embora Mauss tenha insistido no caráter de obrigatoriedade dessas práticas, às vezes dando a aparência de atos automáticos, tanto a dádiva quanto a contradádiva são práticas de dupla verdade, livres e obrigatórias, envolvidas sempre numa "aura de incerteza":

O intervalo tinha como função colocar um véu entre a dádiva e a retribuição, permitindo que dois atos perfeitamente simétricos parecessem atos singulares, sem relação. Se posso definir minha dádiva como uma dádiva gratuita, generosa, que não espera retribuição, é porque existe um risco, por menor que seja, de que não haja retribuição (sempre há ingratos), logo, um suspense, uma incerteza, que permite a existência, como tal, do intervalo entre o momento em que se dá e o momento em que se recebe. (Bourdieu 1996, pp. 165-166)

Os agentes, empenhados nos negócios da prática cotidiana, desconhecem essa duplicidade da troca de dádivas: "quem dá e quem recebe colabora, sem sabê-lo, com um trabalho de simulação que visa negar a verdade da troca, a dádiva retribuída, que significa a anulação da troca de dádivas" (idem, p. 166).

Esse tipo de prestação social é uma espécie de transação econômica denegada. Como não há uma correspondência propriamente econômica na troca de dádivas, ou seja, na perspectiva de Marx, redução de trabalho concreto 
a abstrato, logo, troca de equivalentes econômicos, a maior probabilidade de ocorrência é de uma assimetria econômica não calculada, permitindo concluir-se que o essencial são as relações contraídas, generosas, hospitaleiras, desinteressadas etc. $\mathrm{Na}$ troca de dádivas, os bens presenteados, justamente por não se reduzirem a um denominador comum econômico, são sempre bens qualitativamente singulares, ou seja, valorizados segundo padrões propriamente simbólicos, não-econômicos e, às vezes, antieconômicos, pois a prestação implica uma retribuição talvez mais cara do ponto de vista econômico. ${ }^{3}$ Segundo Pouillon (1995, p. 107), esse aspecto da troca de dádivas é, em geral, esquecido: ao contrário do empréstimo e do crediário, não se restitui o mesmo bem nem se contabilizam materialmente os presentes dados e retribuídos, permitindo também concluir-se que a racionalidade econômica, do puro cálculo, está tacitamente excluída do horizonte da dádiva, embora, e nisso reside um dos aspectos essenciais de sua "dupla verdade", a troca de dons e contradons "não exclui jamais completamente a consciência da lógica da troca" (Bourdieu 1997a, p. 229). Muito embora também seja, mas não exclusivamente, uma modalidade específica de circulação de mercadorias (bens e serviços), na qual a forma dinheiro ou está ausente ou desempenha papel muito indireto (não é de bom-tom presentear com um cheque preenchido, dispensando-se do trabalho de procurar o presente adequado, nem deixar a etiqueta de preço no presente, explicitando assim o seu traço de verdade econômica), a troca de dádivas constitui, se se quiser, um fluxo inter e intracultural de bens (Appadurai 1991, p. 28), com um regime de valorização diverso do econômico. É interessante registrar, como ilustração, a tensão entre a troca de dádivas e as trocas econômicas, pois muitas vezes a segunda invade o espaço da primeira, e vice-versa: pensamos nas atuais listas de presentes de casamento, que praticamente eliminam a dimensão desinteressada e não-econômica do presente, quase reduzindo-o a uma transação explicitamente interessada e econômica (à análise caberia desvendar a partir de qual posição social e com quais disposições os agentes praticam esse tipo de transação). Um exemplo de invasão em sentido contrário pode ser visto nas fundações de direito privado, quer de benemerência social, quer de pesquisa etc., instituições que não visam à valorização econômica imeditata, sendo, em alguns casos, flagrantemente antieconômicas, embora mantidas pelo capital.

\section{Um exemplo: A comunicação científica}

"Parece mesmo que a teoria da dádiva ocupa uma espécie de espaço social", escreve Pouillon (1995, p. 109), "uma área de aplicação assaz universal, 
como pretendia Mauss, que podemos resumir numa fórmula: fora dos caminhos batidos. Isto significa fora dos circuitos de troca que as sociedades estabelecem, e que os etnólogos se têm proposto descrever". Uma surpreendente aplicação da teoria da dádiva encontra-se na descrição feita por Hagstrom (1982) da comunicação científica. Segundo esse autor, as contribuições dos cientistas aos periódicos especializados possuem todas as características da dádiva. De fato, os autores presenteiam livremente (ou seja, ao mesmo tempo interessada e desinteressadamente) ${ }^{4}$ o campo científico com o resultado de suas pesquisas, por meio das publicações especializadas, e não recebem pagamento em troca. ${ }^{5}$ Além disso, as comunicações estabelecem, como a troca de dádivas, regras recíprocas de direito e moral. Não se trata, evidentemente, de contradons do mesmo tipo, mas de deferências e reconhecimentos retribuídos pelos pares-concorrentes ao autor do artigo (de muitas formas, tais como a prioridade da descoberta, o direito à eponímia, títulos etc.). Mais ainda, a troca de dádivas estabelecida pela comunicação científica impõe aos cientistas obrigações morais: os resultados das pesquisas só podem ser publicados nos periódicos especializados; o cientista que procurar status fora desse intercâmbio, na imprensa profana, com a esperança de furtar-se ao julgamento dos comitês de redação dos periódicos especializados, corre o grave risco de condenação. ${ }^{6}$ Assim como na troca de dádivas, os interesses implícitos - reconhecimento, imortalidade, prêmio Nobel etc. - não podem ser explicitados, ou seja, cinicamente trazidos à luz:

A organização da ciência consiste de uma troca de reconhecimento social por meio de informação. Mas, como em toda troca de dádivas, a expectativa de retribuição do presente dado (o reconhecimento) não pode ser publicamente explicitado como o motivo para a troca de dádivas. Um presente é suposto como dado, não na expectativa de uma retribuição, mas como expressão do sentimento do doador com respeito ao beneficiário. (Hagstrom 1982, p. 22)

Segundo Hagstrom, o regime de dádivas e de contradádivas é importante na ciência porque, ao criar obrigações particulares, específicas da ciência, limita a ação da racionalidade econômica no campo científico. A conseqüência é da maior importância: além de ser a troca de dádivas uma modalidade eficaz de controle social da ciência, preserva-se a autonomia, sempre relativa, do campo científico, constantemente ameaçada pelos poderes externos, político e econômico. 


\section{A escola e as questões do quasi-market}

Um proveitoso diálogo com a teoria da dádiva pode ser encetado por meio de temas que resvalam com os da dádiva: nos referimos especificamente às questões suscitadas pela invasão do mercado (e suas normas, seus valores, regras, ética etc.) no campo educacional. Recentemente, um número inteiro da Oxford Studies in Comparative Education foi dedicado ao estudo do quasi-market educacional e suas conclusões genéricas são as seguintes.

Durante a década de 1980, governos de países industrializados despojaram-se da responsabilidade de planejar, organizar e prover serviços antes considerados básicos. Introduziu-se vitoriosamente, com especial impacto nos chamados welfare-states, a ideologia do mercado. A idéia básica é que a disciplina do mercado assegura a sobrevivência apenas dos serviços de alta qualidade, fazendo perecer os de baixa qualidade, mormente os do Estado, considerados em geral como ineficientes. Considera-se, portanto, que o uso dos mecanismos de mercado ajuda não apenas a resolver problemas econômicos, como também contribui para o bem-estar da população por meio do incremento das liberdades individuais resultante das restrições impostas ao Estado. Considera-se também que a competição entre os fornecedores de bens e serviços (públicos e privados) aumenta a qualidade dos produtos de todos os fornecedores e assegura aos consumidores boas trocas no mercado. Inevitavelmente, tais idéias foram estendidas à oferta dos serviços educacionais. A conseqüência imediata foi a reorganização, nas décadas de 1980 e 1990, por muitos dos países industrializados, de seus sistemas de ensino no sentido do mercado. Passou-se a dar maior apoio financeiro e ideológico ao setor privado, acompanhado de uma crescente nebulosidade nas distinções entre os setores público e privado do sistema de ensino, praticamente empurrando todas as escolas para a competição no mercado. ${ }^{7} \mathrm{O}$ argumento básico utilizado em apoio ao processo é uma adaptação da idéia geral: a competição entre as escolas incrementa sua eficiência. Visivelmente, isso tem levado, ao contrário, a um aumento da desigualdade entre as escolas e a um aumento das desigualdades nas experiências educacionais das crianças em termos de gêneros, classes sociais e etnias.

Mas essas idéias e essa situação não foram pacificamente aceitas. "Muitos críticos acreditam que a educação deveria ser vista como um bem público e que é um grave erro tratar a oferta de escolarização como uma mercadoria negociável" (Walford 1996, p. 8). Na análise deve-se considerar, além disso, que "a natureza do mercado introduzido na educação não é 
a mesma do encontrável na indústria e na maior parte dos serviços industriais" (idem, ibid.). O termo quasi-market pretende dar conta dessas questões. Ele indica que as forças do mercado introduzidas na educação, como observado acima, diferem das encontradas no mercado clássico de bens e serviços. Essas diferenças podem ser sintetizadas nos seguintes termos: a) o dinheiro não muda de mãos entre compradores e vendedores (mas bônus reembolsáveis pelo governo); b) as famílias são forçadas a fazer algum investimento nesse mercado (que, desse modo, não é tão livre) e elas mesmas realizam serviços similares; c) as instituições escolares, mesmo particulares, não são propriamente privadas e não necessariamente se orientam apenas pela lógica da maximização dos lucros; d) os bens oferecidos são regulados por forças extramercado (a questão do currículo nacional); e) desse modo, alunos e pais de alunos não podem escolher qualquer produto; f) o comprador não é necessariamente um consumidor; g) as crianças só têm uma única chance de receber educação básica - "se uma escolha errada é feita, os custos pessoais são elevados" (idem, ibid.); h) finalmente, o mercado escolar difere do mercado clássico porque a escolha pode transformar diretamente o produto (por exemplo, pode-se escolher uma pequena escola para educar os filhos; se muitos outros o fizerem, a escola deixará de ser pequena). Em resumo, tem-se aqui uma situação cheia de paradoxos, perigos e problemas sociais muito delicados, que pode receber da teoria da dádiva contribuições provavelmente esclarecedoras.

\section{A dádiva e a violência}

É interessante, a título de complementação, identificar uma intercessão entre as análises de Mauss e Norbert Elias (1994) sobre a cultura. Para este, o processo civilizacional significa um recuo das barreiras naturais, ou seja, progresso material e domínio da natureza e, simultaneamente, transformação do comportamento humano (mudança nos traços das atitudes vividas em sociedade) e contenção da violência. Para Mauss, a troca de dádivas é um claro índice de civilidade, sobretudo no que tange aos mecanismos sociais de contenção da violência: a troca de dádivas não elimina a agressividade (mesmo porque o potlatch, modalidade agonística de troca de dádivas praticada nas culturas estudadas por Mauss, podia, eventualmente, terminar em luta de morte na disputa pelo maior prestígio entre os chefes dos clãs) ${ }^{8}$, mas seguramente é uma prática que restringe a violência, coloca-a em limites morais toleráveis por meio de um universo de costumes religiosos, econômicos, morais, jurídicos etc., valorizando a hospitalidade, a generosidade, a etiqueta e o 
prazer estético (sendo, por isso mesmo, uma espécie de prática social de elevado interesse para o estudo da cidadania). Escreve Mauss (1995, pp. 278-279):

As sociedades progrediram na medida em que elas mesmas, seus subgrupos e, enfim, seus indivíduos souberam estabilizar suas relações, dar, receber, enfim, retribuir. (...) É desse modo que o clã, a tribo, os povos têm sabido - e é desse modo que amanhã, nosso mundo dito civilizado, as classes, as nações e também os indivíduos devem saber - se opor sem se massacrar e se dar sem se sacrificar uns aos outros. Eis um dos segredos permanentes de sua sabedoria e sua solidariedade.

Mas, e eis aqui outro aspecto de sua "dupla verdade", a troca de dádivas não exclui a violência simbólica: a dádiva é uma instituição sancionadora da amizade, mas, paradoxalmente, encoberta sob práticas de liberalidade estabelece e reproduz relações de dominação simbólica:

Receber quer dizer concordar em mostrar-se devedor de alguém e, em certa medida, pagar essa dívida em termos de humildade e delicadeza. Compreende-se então imediatamente que não retribuir é também, de certo modo, uma maneira de o fazer: é conformar-se com ser minimizado, reconhecer o ascendente e aumentar o prestígio do doador; não retribuir pode significar uma ruptura, mas pode também confirmar uma submissão. (Pouillon 1995, p. 108)

A dádiva funciona como uma espécie de operador prático entre dois conjuntos de possibilidades: no que tem de regime igualitário, a dádiva reforça a comunhão entre iguais; no que tem de regime desigual, a dádiva contribui para fixar as posições de dominante e dominado; mesmo no regime igualitário, a dádiva pode resultar num efeito de dominação, assim como no regime desigual, pode nivelar os agentes - por força do simples ato de troca (Bourdieu 1996, p. 173).

\section{"Dever-se-á dar, dever-se-á retribuir?" - Interesses e estratégias}

Além do conceito de campo, os de interesse (há tantos interesses quanto campos), estratégia e habitus são, segundo Bourdieu, essenciais para lançar luz sobre práticas tão resistentes à apreensão científica quanto as da dádiva. Essa modalidade de economia denegada, de economia antieconômica, 
que é a troca de dádivas, possui todos os ingredientes que fazem dela a forma modelar de economia das trocas simbólicas: na dádiva, os agentes entram "intencionalmente sem intenção", ou seja, sem cálculo consciente, mas, ao mesmo tempo, previamente predispostos pelo habitus incorporado a entrar num jogo cuja verdade (de troca e de domínio simbólico) é encoberta por eufemismos sutis. Na troca de dádivas, os agentes agem comme il faut, ou seja, respondem adequadamente às questões de quando e como dar e retribuir - o momento certo, a circunstância apropriada, isto é, desenvolvem as estratégias adequadas aos interesses em jogo - porque suas ações são guiadas por todas as disposições adquiridas que os ligam ao intercâmbio, ou seja, pelo habitus que não os faz indiferentes aos jogos e apostas envolvidos na dádiva, de tal modo que suas ações "caem bem" ${ }^{\text {. }}$.

\section{Valores e conhecimentos}

A idéia de que há uma ligação muito íntima entre conhecimentos e valores é muito antiga. Do nascimento da filosofia até as modernas teorias da inteligência, valores e conhecimentos foram vistos, o mais das vezes, como dotados de liames internos, não externos, ou seja, meramente instrumentais. É muito provável que a perseguição do ideal de uma ciência livre do ponto de vista axiológico, tendência recente no conhecimento e muito forte sobretudo após o nascimento das ciências sociais, seja o reconhecimento dessas ligações íntimas, nesse caso consideradas indesejáveis e até perturbadoras do conhecimento sereno a que deve almejar o cientista. Não é nosso propósito recuperar aqui a discussão, muitas vezes longa, da relação entre ciência e valores, mas apenas indicar que toda perspectiva de conhecimento é produto de uma posição diferencial no espaço das posições sociais, isto é, de uma posição num campo determinado (com seus jogos e interesses, ou libidos, ou ilusões), perspectiva esta mediada pelas disposições incorporadas, na forma de habitus, que constituem a retradução simbólica dessas posições sociais e de toda a trajetória que a elas conduz (trajetória que incorpora a cultura familiar, a mediação escolar etc.). Não é por acaso que se pode afirmar, em análise epistemológica, que o valor informacional - poderse-ia até dizer: o marco cultural - dos dados acumulados nos campos simbólicos "depende justamente da existência de pessoas interessadas que os organizam e lhes atribuem significado, transformando-os em informação" (Machado 1995, p. 66). A operação cognitiva de atribuir significado está imbricada com o interesse, permitindo-se aventar a hipótese de que a diferentes regimes de valor, ou seja, de interesse, correspondam as distintas formas de classificação que estão na base das atribuições de sentido. Parece que essas 
proposições põem em bases novas a eterna e jamais resolvida discussão sobre a relatividade dos valores.

\section{Considerações finais}

Tudo indica que a teoria da dádiva é uma aparelhagem adequada à apreensão dos mecanismos subjacentes às trocas simbólicas nas sociedades contemporâneas. Pense-se, só para citar uma lista que pode ser bastante acrescida, nos ensinamentos morais veiculados pela literatura infantil (ver, por exemplo, a fábula "O leão e o ratinho"), nas disputas suntuárias por fama entre os homens de prestígio (cujo veículo mundano por excelência é o colunismo social), nas estratégias matrimoniais das classes sociais, nas relações domésticas (o aleitamento materno é considerado a mais pura forma de dádiva), na regulamentação jurídica da previdência e do mercado artístico, nas trocas acadêmicas (comunicação científica, concessão de títulos etc.), nas relações de amizade como integrante do capital social dos indivíduos, nas trocas propriamente escolares e nas questões que emergem das relações entre a educação e o mercado.

Parece que a troca de dádivas é irredutível tanto ao objetivismo, que nela vê apenas o automatismo de obrigações contratuais, quanto ao economicismo, decisivamente inclinado a desconsiderar a autonomia própria dessa prática em relação aos trânsitos regidos pela lógica do campo econômico. Também é possível que o finalismo, propenso a considerar as ações dos indivíduos como escolhas deliberadas e racionais (Bourdieu 1992, pp. 72 78), não dê conta da ambivalência e da "dupla verdade" da dádiva (obrigação/ liberdade; ação consciente/inconsciente; interesse/desinteresse, igualdade/ dependência, projeto/protensão etc.).

O sugestivo estudo das homologias estruturais dos campos, das especificidades dos interesses e das estratégias empregadas pelos agentes para satisfazê-los, bem como os estudos da lógica do quasi-market e da troca de dádivas como tipo modelar de intercâmbio não explicitamente econômico, sem dúvida lança luz nas relações entre o campo simbólico e o econômi$\mathrm{co}$, entre os valores (normas e regras) e os saberes (interiorizados e exteriorizados nas práticas), podendo, por conseguinte, resultar num conjunto de conhecimentos capazes de redimensionar os problemas do campo educacional advindos dos desafios postos pela cidadania, simultaneamente nas esferas intra e extramercado, e, eventualmente, desembocar numa "promissora trilha que pode significar uma efetiva saída para os impasses e dilemas em que a tácita mercadorização nos mergulhou" (Machado 1997, p. 28). 


\section{Notas}

1. Mauss observou que muitas das conclusões de seu estudo eram extensíveis às sociedades modernas (cf. Mauss 1995, p. 258). O autor entendia que uma parte considerável dos costumes das sociedades industrializadas era regida pela lógica da dádiva, ou seja, estava dominada por uma mistura de obrigação e liberdade. Entendia, por exemplo, que a seguridade social, então em desenvolvimento na forma de "caixas de ajuda mútua", e o direito sobre as obras de arte podiam ser pensados com base na economia da dádiva (Mauss 1995, pp. 258-263).

2. É interessante constatar que o tema do intervalo temporal entre o dar e o retribuir, embora registrado no Essai, passou despercebido a Mauss. Na fala a seguir, colhida de uma das fontes do autor, estão presentes a dimensão não-econômica da dádiva e a questão do intervalo temporal: "Suponha que você possua um artigo determinado e que você me dá esse artigo; você me dá sem fixar preço. Não fazemos negócio com isso. Ora, eu dou esse artigo a uma terceira pessoa, que, após certo tempo, decide me retribuir com alguma coisa em pagamento, me presentear com algo" (Mauss 1995, p. 158). Observar, no depoimento maori, a recorrência à não-fixação de preço e ao tempo decorrido entre a dádiva e a retribuição.

3. "Nada ilustra melhor essa ambivalência do que a peculiaridade lingüística detectável no vocabulário indo-europeu e particularmente evidente na língua alemã: desdobrado o seu conteúdo semântico, a palavra gift tem em inglês o sentido de 'dádiva', e em alemão o de 'veneno'" (Pouillon 1995, p. 96).

4. Talvez seja conveniente lembrar que os cientistas, ao contrário do que dizem as descrições mais hagiográficas do campo científico, têm interesses; ocorre que seus interesses são propriamente científicos, em particular, e simbólicos, em geral, não são interesses propriamente econômicos (não se poderá fazer um cientista correr atrás do pregão da Bolsa).

5. Aqui é preciso observar que se trata de artigos em periódicos especializados dirigidos aos pares-concorrentes do campo científico. Quando escrevem para um público mais amplo, os cientistas recebem, naturalmente, direitos autorais por suas obras, mas, mesmo aqui, o dinheiro geralmente não é o móvel da publicação.

6. A questão é complexa. De um lado, há que considerar a perda da referência pública da atividade científica, ou seja, a auto-restrição da comunicação dos cientistas a um nicho formado por pares-concorrentes que compartilham uma linguagem inacessível ao público leigo, decorrência do processo de autonomização e fechamento do campo científico (cf. Jacoby 1990), e, de outro, a tentação de abertura que acomete o fastthinker, intelectual formatado pela televisão e comensal de um fast-food cultural digestivo e altamente comerciável (cf. Bourdieu 1997b)

7. A respeito da imprensa, Bourdieu mostrou que, ao contrário, a competição por audiência uniformiza e nivela por baixo todos os produtos oferecidos (cf. Bourdieu 1997b).

8. O potlatch era uma forma típica, relativamente rara, das prestações totais estudadas por Mauss (e que foi exaustivamente descrita por Boas, de quem Mauss colheu as 
observações etnológicas), caracterizada por um festa perpétua em certa época do ano, na qual se sucediam banquetes, feiras, mercados, ritos etc., tudo constituindo uma assembléia solene da tribo. O aspecto mais relevante do potlatch era a exacerbada rivalidade em todas as práticas, chegando mesmo a conflitos mortais entre os chefes dos clãs e à destruição "puramente suntuária" das riquezas custosamente acumuladas.

9. É bem possível que tenhamos aqui utensílios conceituais proveitosos no estudo do fracasso, de sanções e seletividades escolares: os agentes não predispostos, por um longo trabalho prévio de inculcação familiar, às trocas tipicamente escolares (à comunicação escolar, às disciplinas escolares, enfim, ao currículo) têm elevadas chances de se revelar indiferentes (nem interessados, nem desinteressados) à economia propriamente escolar (cf. Nogueira, s./d.).

Recebido para publicação em Abril de 1998.

\title{
Disciplinary rules of value, of knowledge: Some topics concerning the gift anti-economy
}

\begin{abstract}
The study of the areas structures homologies, the interests specificity and strategies used by the agents, as well as the study of the quasi-market logic and gift exchange as interchanges model type not explicitly economic that clarify the relations between the symbolic area and the economics and knowledge which could result in some knowledge able to re-measure the problems of the educational area coming from the challenges placed to citizenship, into infra and extra market spheres at the same time.
\end{abstract}

\section{Bibliografia}

APPADURAI, Arjun (org.). La vida social de las cosas. Perspectiva cultural de las mercancías. México, D.F.: Grijalbo, 1991.

BOURDIEU, Pierre. Outline of a theory of practice. Cambridge: Cambridge University Press, 1992.

. "A economia dos bens simbólicos". In: BOURDIEU, Pierre. Razões práticas. Sobre a teoria da ação. Campinas: Papirus, 1996, pp. 163204.

. Méditations pascaliennes. Paris: Minuit, 1997a.

. Sur la télévision. Paris: Liber, 1997b.

ELIAS, Norbert. O processo civilizador. Uma história dos costumes. $2^{\mathrm{a}}$ ed. Rio de Janeiro: Jorge Zahar, 1994, 2v. 
HAGSTROM, Warren O. "Gift giving as an organizing principle in science". In: BARNES, Barry e EDGE, David (orgs.). Science in context. Reading in the sociology of science. Milton Keyne (England): The Open University Press, 1982, pp. 21-34.

JACOBY, Russell. Os últimos intelectuais. São Paulo: Edusp/Trajetória Editorial, 1990.

MACHADO, Nilson J. Cidadania e educação. São Paulo: Escrituras, 1997. . Epistemologia e didática: As concepções de conhecimento e inteligência e a prática docente. São Paulo: Cortez, 1995.

MAUSS, Marcel. "Essai sur le don. Forme et raison de l'échange dans les sociétés archaïques". In: MAUSS, Marcel. Sociologie et anthropologie. $6^{\mathrm{a}}$ ed. Paris: PUF, 1995, pp. 146-279.

NOGUEIRA, Maria A. "Convertidos e oblatos: Um exame da relação classes médias/escola na obra de Pierre Bourdieu". Belo Horizonte, s./d. (mimeo.).

POUILLON, François. "Dádiva". Enciclopédia Einaudi. Porto: Imprensa Nacional, Casa da Moeda, 1995, v. 28, pp. 95-113.

WALFORD, Geofrey. "School choice and the quasi-market". Oxford Studies in Comparative Education, v. 6 (1), 1996, pp. 7-15. 